\title{
Language Contact, Cognitive Circularity and "WE"
}

\author{
Robert Nicolaï \\ Institut universitaire de France, Laboratoire d'Histoire des Théories \\ Linguistiques (CNRS Paris) \\ nicolai@unice.fr
}

\begin{abstract}
The issue of 'language contact' has been widely explored from the perspectives of empirical description and theoretical development, as well as from sociolinguistic, societal and cognitive angles. I would like to broach the subject from a different view, to deepen reflections of an epistemological and methodological order, building on my "distanced" (but empirically grounded) examination of language contact and semiotic dynamics (Nicolaï, 2011, 2017a, 2017b). Several notions will be further explored and specified here, such as: givens, constructs, historicity and WE. The goal is to structure research trajectories by highlighting both the relative relativity of our epistemic understanding and the extent of our subjectivity in context. On this basis, positions can be taken, most notably on the possible circularity of the hypotheses we posit. General learnings can be gleaned from these elements for grasping language contact, the dynamics driving their transformation, as well as general processes for ascribing meaning and developing significance, which in the end converge with current hermeneutic approaches and enactive views.
\end{abstract}

\section{Keywords}

language contact - historicity - communication actors - epistemology - circular reasoning - hermeneutics - enaction 
en souvenir de Michel Arrivé

\section{Overview}

Research on language contact is now a well established field. Basic intuition tells us that what is generally meant by 'contact' is not perceived on the phenomenal level as a primary fact since, by definition, for 'contact' to happen, there must be elements which are not yet in contact! Whether such 'contact' is identified as a phenomenon or as a concept, it always entails (an entering into) relations between entities, the homogeneous status of which can only supposed and/or inferred. This notion of contact is thus developed by the $a c$ tors of communication (ordinary speakers and/or language descriptors) and is recognized for all practical purposes. For example, in order to analyze linguistic phenomena, to theorize and build knowledge, or for purposes of an entirely different order to do with social, symbolic, political dynamics. Thus through these links to empiricism and the distance which its recognition entailsincluding through description — what is denoted by 'contact' refers at once:

- to the positive status of a phenomenal manifestation which entails its understanding in the framework of 'phenomenologies' taken as objects of study,

- to a theoretical status, the vocation of which is, on one hand, to structure the conceptual level enabling the description and analysis of what can be subsumed under the term 'contact', and, on the other hand, to develop the related methodological tools,

- to an epistemological status which tends to include this type of study among processes of establishing knowledge which we develop implicitly or explicitly. This can then, depending on which assumptions, premises and theoretical principles have been chosen, introduce the essentialization of the phenomenon and concept (a "metaphysical" approach), or

1 Let us specify that by 'phenomenology' I mean a construed universe which depends on the type of relevance chosen and is constituted by that which enables it to function. In this case the phenomenology is temporarily treated as an object which can be accounted for, and its description is naturally linked to the relevance under consideration. 
its idealization, its demotion or its rejection (an "ideological" premise), or, finally, to increased precision in its analysis and contextualized study (an "empirical" approach).

This means that it is important to take into account the fact that, in the process of identifying a language contact' phenomenon, we are descriptors with our own relevance and impact in its interpretation and in the development and/ or recognition of the phenomenologies which manifest it. (Nicolaï, 2011, 2012). Let us illustrate these with a few examples: 'mixed languages', 'code-switching', 'convergence areas' and other entities of the same nature are phenomenologies developed in relation to the notion of 'language contact', and it has become possible to account for them "rationally" 2 as empirical objects which can be understood and described within the universe where this notion of 'contact' is recognized and functionalized.

That being said, since the first studies in the $19^{\text {th }}$ century and innovative work in the mid $20^{\text {th }}$ century, new avenues have been opened up, it is no longer marginal nor pioneering to examine language contact, and this is largely confirmed by the extensive scientific literature it has generated and the academic recognition it has obtained. This is one of the reasons why it can be of interest to reflect upon what it means to partake in such research dynamics. Otherwise force of habit can induce analytical sclerosis, a dulling of ideas and, in the end, negation of the spirit behind the research.

Therefore I have chosen three exciting questions I hope will keep us awake. ${ }^{3}$ They are:

- How does meaning emerge in these varieties, both in terms of cognitive activity and socially significant activity?

- What of our very conception of what language contact is, in both its methodological and epistemological dimensions?

2 By this label I refer to the forces underlying the creation of knowledge which, when applied to a given field of research, aim to extend and saturate (in the sense of bringing it to fulfillment) the epistemic space it opens through rational application and the systematic completion of all possible areas of ignorance which, grounded in knowledge explicitly recognized at an instant $\mathrm{T}$ in its implementation, authorizes the theory behind its consideration. See Passeron (1991), as well as Nicolaï (2017b).

3 They were explicitly asked by Élodie Blestel and Santiago Sánchez Moreano, organizers of the "Journées d'étude: Variedades de español en contacto con lenguas amerindias: sistemas en contacto o prácticas lingüísticas heterogéneas", held in Paris (12-13 June, 2017), in the study plan they drew up to structure the debates and steer discussions. The present article thus contributes to the reflections inspired by the questions they asked. 
- What of the manner in which we build our corpora, given that they should illustrate the dynamism and heterogeneity of language practices?

Such questions translate what I call positive concern in the process of epistemic development and construal of representations in which we continuously participate. How is this positive concern manifested? Through meticulousness in epistemological reflections developed in counterpoint to the processes of empirical description and theoretical constructions we carry out. Let us begin by noting that these questions presuppose a fact which is often ignored: we are at the center of this reflective questioning, because, on one hand, "meaning" can only emerge through us and for us - but what do we mean by "meaning"? and on the other hand, our subjectivity and capacities for objectivization and rationalization are at play in the definition, identification and/or construction of the "objects" we are attempting to understand. We will return to this matter below.

However, before proceeding and on a general level, let us consider what we seek - and what we find - when we attempt to "account" for perceived empirical phenomena and/or the organization establishing and articulating them. To do so, let us begin by examining what is sometimes denoted by a grand word which raises philosophical issues: reality. That which, as seekers of "meanings" ('ordinary meanings' or 'epistemic significance') we attempt to

4 When precision is called for, I generally call upon the distinction established by Benveniste $(1966,1974)$ where the term 'meaning' refers to semiotics and the term 'significance' to semantics: "Semiotics is characterized as a property of a given language, semantics denotes activities on the part of speakers enacting the language" [Le sémiotique se caractérise comme une propriété de la langue, le sémantique relève d'une activité du locuteur qui met en action la langue (1974: 225)]. Within the dynamic framework I favor, I most often distinguish between "creation/development" of meaning, which pertains to words in languages considered from a systemic angle, and "ascribing significance" which pertains to usage and transmission considered contextually adapted to the proposition such that it will be understood in and through exchanges. But of course the word 'meaning' is also widely used with a much blurrier definition. Let us note that such distinctions between semiotics and semantics are only relevant to the highly abstractly objectivized functionalization denoted by these terms; in other words, it is not because they implement dynamic processes that the latter are necessarily analyzed. The issues of emergence and construal of meaning, the development of significance and of understanding of these dynamics are not considered. 
understand - in the field of linguistics, of course, but also elsewhere. What can be said about this reality? Without entering in metaphysical debates, I will imagine it - I will represent it to myself and to you — as being constituted of a triangle where the sides correspond to three distinct but interdependent dimensions, each necessary for the recognition, understanding and establishment of this reality (Nicolaï, in press a). These are:

- The dimension of phenomena. These, through —and depending on - the segmentation we apply to the outside world and how we understand it, bear testament to the objectiveness of this reality. Naturally, they are susceptible of being analyzed (e.g. language and linguistic data) and they are necessary as empirical media to perceive and understand this reality, provided that one recognizes that it does not depend solely on speculative thought.

- The dimension of the representations correlatively recognized and/or developed with regards to the phenomenal data. These representations entail at least partially validated decontextualization (or at least shifted and historicized recontextualization), objectivization and the inscription in signs of what this three-dimensional reality is supposed to indicate, transmit, establish, present (e.g. the reality of language contact, whether taken as an evidential or construct - terms which I shall specify below).

- And lastly, the dimension of rational and/or social validation applied to these phenomena and representations, because without validation in effect authorizing the refunctionalization in context of what is "recognized and represented", there would be no way of ascribing meaning to these phenomena and representations, no way for them to emerge, become established, obvious, transform within the common space where we develop our epistemic activities (whatever their nature).

A certain reality is thus affirmed, confirmed, takes on meaning ${ }^{5}$ and "displays significance", at the heart of the triangulation of these three dimensions (and one must admit that the "academic-scientific" validation at play in universities and research is only a sub-variety (a preconstrained and coded variation) of this rational and social validation). To clarify all of this, I will specify what I mean by the terms givens and constructs (cf. Nicolaï, 2012, 2017a) which I used above in relation to representations.

5 At the risk of repeating myself, let me once again stress that "meaning" emerges by us and for us. 


\section{Givens and Constructs}

\subsection{Givens}

By this term I denote a specific sub-category of our representations: those we consider stable, as pre-existing us and therefore de facto imposed (as... "givens"! ${ }^{6}$ through developments in our personal and collective histories. Come under this sub-category all entities which exist independently of us, but which nonetheless derive from our activities. For example: our languages, linguistic and social structures, cultural patterns, phenomenologies resulting from language contact and the other entities we have effectively created as humans-whether intentionally or not-; entities which could not exist without us.

Let us also highlight that what I am accounting for here is entirely determined by historicity, which has manifest effects in the construal of our representations, attitudes, behavior and analyses, and eventually ends up by being integrated in the givens which we interpret and functionalize as signs.

\subsection{Constructs}

Whereas givens - even though they evolve-are considered stabilized representations and show a certain degree of independence as to the contexts where they are used since their existence pre-dates us and they are constituted as signs, constructs do not pre-date us. They are representations in the making, we develop them on the fly within a specific context. Thus they belong to our present and are entirely determined by ongoing contextualization. That being said, they do not appear out of nowhere and depend to an equal extent on both pre-existing stabilized representations and the context in which they are developed. Constructs articulate around each other, intermingle, and are continuously elaborated (on) and reinterpreted through the filter of our historicity, upon which they depend just as do givens.

Once they have become stabilized in the forms of routines or signs, they in turn will then function as givens and no longer as constructs. They thus partake in the process whereby forms are created, meaning is developed, elements take on significance, and in which we can but participate, whether

6 In French I chose the word évidence although it is not entirely satisfactory because it can be misleading both in its ordinary and its philosophical definitions, but has the advantage of denoting how objects of this type are received/perceived by individuals confronting them. The English given does not lead to such confusion. In any case, the definition provided here should clarify its use. 
our goal is "scientific" epistemic conceptualizations or a simple chance exchange of words. ${ }^{7}$

In other words, constructs are entities which share certain characteristics with givens, which are the following: they are positively identifiable, they are obvious to us and they specifically result from human processes and developments; they do not however share the characteristic of being historically stabilized. In yet other words, this or that standard, this or that phenomenon created in the instant are constructs within the instant, but have the potential of becoming, if they are adopted, givens for future use, and perhaps even for generations to come.

\section{$4 \quad$ Historicity}

To specify what I mean by given and construct, I have called upon the notion of historicity. ${ }^{8}$ With the term, I situate myself at the point where we insert ourselves in our communicational practices at instant $\mathrm{T}$ through the-possibly reconstructed-biases and retention of characteristics and specificities retained from our communicational experience at instant T-1. This historicity is thus inseparable from our understanding of the world and our interpretation of signs. It retains reference to past occurrences in the form of utterances, routines, and dynamics which concern us individually or collectively, and which restructure (which we transform) in new representations and practices susceptible of being assessed within the interaction and shared in a discursive future. Historicity preconstrains the communicational process, leaves its mark on our practices, on the forms we use, on languages, and develops, perfectly naturally, through our daily linguistic activities of which it is partially the result. But because it depends on human actors, it entails (and induces) a constant process of reframing and transforming previously used signs, which are

7 In another domain, these thoughts also converge with the ethnomethodological approaches introduced by Garfinkel (1967); see Nicolaï (2016a, 2017b) for more details on their comparison. Broader explorations (rather than research paradigms) emerge once the focus is on this continuous process of elaborating (on), the consequence of which is to create new forms, which will eventually be functionalized in turn.

8 Notion that I had already implicitly introduced (1986) in analyzing the relations between what I called 'norme 1' (represented standard) and 'norme 2' (interactional standard) in what I identified as the process for the 'topicalization' [thématisation] of meaning - the process which "comes down to objectivizing 'norme 2 ' in terms of 'norme 1 '. I continued specifying and furthering the notion in my later texts $(2001,2011,2017 \mathrm{a}, \mathrm{b})$. 
recontextualized and refunctionalized anew each and every time at the instant of their actualization.

This entails that, being interactors, we are at once the guarantors, transmitters and "transformers" of this historicity, which continuously inscribes in our epistemic construals, in our behavior, and in the situation which is unfolding, the effects of what is happening and then the remembrance of where that led. This is how we contribute to creating meaning and to developing effectiveness in ascribing significance within the communicational framework which is chosen (though not necessarily functional) for the occasion, at instant $\mathrm{T}$ of our activity. ${ }^{9}$

From this, one understands that this process which, through the constant reminder of the "already-been-there-already-done-that-in-such-and-such-acontext" present in the background of our communicational activities, creates the juncture between the world and individual and social subjects, it objectivizes (and/or reconstructs) the outcome and-depending on the nature of the "remembrance" - gives significance to the matter at hand. Let us now return to the notion of 'contact'.

\section{'Language Contact' as a Phenomenology, as a 'Given' and as a Concept}

Language contact defines the setting of a phenomenology. It is in fact concrete and empirically delimited phenomena which attest to 'contact', in the form e.g. of the above-mentioned 'mixed languages', 'convergence areas', 'codeswitching' and many more besides. Today they are recognized as givens to be described. At another level, processes such as grammaticalization, typological

9 One may note that this notion of historicity is implicitly present in currently developing enactive theories (see e.g. the biologists and philosophers H. Maturana and Fr. Varela (1987) and the work building on their approaches). These two authors thus posit: "It is our history of recurrent interactions that makes possible our ontogenic structural drift in a structural coupling that affords interpersonal coordination of actions; this takes place in a world we share because we have specified it together through our actions. This is so obvious that we are literally blind to it. Only when our structural coupling goes awry in some dimension of our existence do we realize (if we reflect on it) the extent to which our behavioral coordinations in the manipulation of our world and communication are inseparable from our experience ([1987] 1998: 232-233)". And also: "we are continuously immersed in this network of interactions, the results of which depend on history. Effective action leads to effective action: it is the cognitive circle that characterizes our becoming, as an expression of our manner of being autonomous living systems ([1987] 1998: 241)". This is a very interesting convergence, all the more so as the approaches are completely independent! 
reelaborations (in that they are manifestations of linguistic transformations), etc. are also susceptible of partaking in 'contact' and being included in this phenomenology.

At yet another level, sociolinguistic approaches often account for processes which are clearly tangent with the issue of language contact, and plurilingual societies and bilingual individuals illustrate the presence of mindful language contact between the actors of communication.

Lastly, language contact can also be comprehended as a concept, particularly when theorized, whereby it contributes to establishing an analytical framework.

\section{The Pre-Extants of 'Language Contact' and the Question of WE}

Before continuing, I will first look at the 'pre-extants' of language contact, without which neither the phenomenon nor the concept could be understood (Nicolaï 2017a). What are these pre-extants?

I have given the first answer: there are the givens I just mentioned. At the same level of relevance there is a parallel pre-extant. It is what I call WE. It requires some thought.

\subsection{The Dynamics of WE and Understanding Languages}

From the perspective of language understanding, what do I place under the scope of this term? Without being independent of the usual meanings of the terms 'community', 'society', 'group', etc. which refer to collective groups or groups considered in their concrete sense, what I mean by WE is not identical to the contents they refer to, whether in their contextual or generic meanings. It does not refer to groups of specific individuals or representations established to encompass them. WE cannot be equated with a collective subject in the sense it is given in sociology and anthropology where it can be identified outside of the communicational space. Moreover, it cannot be considered an entity transcending any sort of "essence".

What I identify by WE conditions at any given instant the process of ascribing significance to the utterances we produce, contributes to determining the transformation of the meaning of the forms used and thus testifies to our presence (both individually and generically) and to our complex state of actors of communication. It is thus the linchpin of the communicational and epistemic processes which we continuously produce through our interactions.

More precisely, I have introduced it to collectively denote the set of dynamics which partake in lending significance to what is exchanged in the communicational processes which the communication actors (us all) actualize 
through their interactions. We know that these dynamics develop in and through languages by integrating and retaining all implications, everything implicit in the trajectories and what remains of the historicity instilled by the communication actors. The latter are moreover determined at once by the structural and cognitive dimensions of understanding and the availability of the forms to which they have access and can put to use.

Being actualized in the hic et nunc, this WE thus introduces-not only in the process of ascribing significance, but also in language- the result of the historicity retained from former communication states and propels it into the time frame of the present instant. This is how it contributes to informing and forming languages as they are actualized in the here and now.

At a very practical level, it can only be objectively recognized and grasped through the dynamics it engenders and in what it actualizes and effectively sets in motion, which is to say the empirical basis which determines the continuous analysis that communication actors undertake of their languages.

\subsection{The Positivity of Languages and WE in Return}

What are the assumptions concerning this WE entailed by the language dynamics which we experience? If one accepts the framework I have established, than one will accept that languages and signs considered as tools for communication "in the fullest sense", ${ }^{10}$ as minutely precise as possible in the processes of denoting and ascribing significance, are at the same time characterized by their availability for new usages and their inherent (indelible) indetermination, which contributes to creating meaning. Languages and signs are dynamic entities, constantly malleable, constantly segmentable and constantly segmented, available for WE, thanks to WE and through WE. Broached as realities in the sense previously specified with my image of a triangle (i.e. characterized at once as complex organizations of phenomena and representations validated by society and functionalized through and for interactions), languages are entities which are necessarily marked by their internal potential for multiplication and differential developments generated by WE and functionalized in context.

In other words, considered from the angle of WE, languages are not only structures to be described, functionalized symbols or even representations of pre-theoretically defined cognitive operations; they are a "pre-formed

10 Though probably unnecessary, I will specify that what I denote by communication is obviously distinct from the theoretical notion of "communication" introduced by cyberneticians in the mid $20^{\text {th }}$ century which entailed a "channel"; such a definition is too narrow for the issues I am addressing here. 
given" - which can be recognized as being composite-which we partake in; a historicized "given" which demands continuous revision and is continuously revised; they are matter to be manipulated — and which we constantly manipulate-both individually and collectively, in their forms and in their meanings.

\subsection{WE as a Blind Spot}

To finish: I retain that the full usage of languages is conditioned by the functional indetermination of the units which compose them, by the afferent historicity which this usage can but integrate, and by the general dynamics of $\mathrm{WE}$, active at the center of linguistic processes, and comprehensible in the multiplication of avatars which, in all ordinariness, communication actors manifest in the functionalization of the plurality of available forms. Forms which, considered at another level of analysis, contribute to linking the comprehension of heterogeneity attested and functionalized in language usage to construed homogeneity, represented by WE, developed by WE and actualized through WE.

This WE dynamic, which apparently functionalizes historicity, determines the development of meaning and the transformation of forms-and languages - thus appears essential for the production both of what will become frozen and what will be modified, of what converges and what diverges in the linguistic space which is one of the essential locations of the manifestations of communication actors; although, within this space, the dynamics of WE constitute a blind spot.

\section{4 'Language Contact' and the Importance of WE}

At this stage, it would appear that language homogeneity is a construct, in constant reconstruction. Each language of course uses its own elements, but also borrows from other languages, which introduces and trivializes the issue of contact; this issue can be (and is) grasped at all levels where the reflexive and analytical work on languages and their actualizations takes place, elaborated by ordinary and academic communication actors.

Were I now to develop this exploration of language contact by more closely examining WE, it would obviously not be through empty words on its efficiency and explanatory value (which remains to be demonstrated); it would be, on one hand, by very concretely applying conceptual tools for categorizing, delimiting, regrouping or splitting and, ultimately, analyzing the phenomena, and on the other hand, by specifying the elements which constitute the phenomenon as precisely as possible at empirical level. Dichotomies such as 'unity / multiplicity', 'homogeneity / heterogeneity', 'identical / different', which partially 
depend on delimiting notions such as boundary, limit or cleft and which all partake in the appreciation, the dynamics, the active and determining intervention linked to this WE, are called upon in this process of delimitation and to the extent where what is at stake with the notion of 'contact' is always a break in continuity in the perception and/or comprehension of what is manifested. It is thus always an evaluative process, an informed decision resulting from a complex rationality, and, in correlation, it is a theorizing operation on what are or what make boundaries which will be decisive. ${ }^{11}$ Naturally this is very concretely grounded in and based on the phenomena, but does not however entail blind imposition of language phenomenology alone. ${ }^{12}$

11 See Nicolaï (2013, in press b, c) for a discussion on the notion of 'boundary', the importance of which becomes obvious once one examines language contact issues.

12 Having reached this stage in our exploration, it is certainly useful to revisit the epistemological approach developed by the philosopher and sociologist G. Simmel ([1923] 1984) who applied it to history and the work of historians, as well as his reflections on the dynamics between what he calls "the causality of aggregate phenomena" [la causalité des phénomènes agrégés] and "the problematic status of simple elements" [le statut problématique des éléments simples] (1984: 141 and sq.). He interestingly notes that "The conceptual or, if one prefers, teleological relation that history maintains with the heterogeneous existential reality which constitutes its object imposes narrow limits on the analyst's intervention. [...] In a manner of speaking, objectivity consists in avoiding the arbitrary and whimsical by respecting certain rules. But it does not entail that observers are slaves of their "object", i.e. that they must literally reproduce the reality with which they are confronted and refrain from any subjective assumptions. [...] The value of objectivity is not linked to the reproduction of the intrinsic characteristics of the object". [La relation idéelle ou, si l'on veut, téléologique que l'histoire entretient avec la réalité existentielle hétérogène qui constitue son objet impose des limites étroites à l'intervention de l'analyste. [...] L'objectivité consiste en un sens à se garder de l'arbitraire et du caprice en respectant certaines règles. Mais elle n'implique pas que l'observateur soit asservi à son « objet », c'est-à-dire qu'il doive reproduire littéralement la réalité à laquelle il est confronté et se garder de tout a priori subjectif. [...] La valeur de l'« objectivité » n'est pas liée à la reproduction des caractéristiques intrinsèques de l'objet (1984: 116)]. Taking inspiration from these reflections is useful for grasping the dynamics behind the creation of meaning in which we participate as ordinary and academic communication actors. I must specify that I was unable to access the original German edition of 1923 (which includes the changes made to the 1905 and 1907 editions), and was also unable to access the published English version (The Problems of the Philosophy of History: An Epistemological Essay, Free Press. 1977) the English version of this Simmel quote is a translation of the French translation (1984) by Boudon of 'Die Probleme der Geschichtsphilosophie', given in reference here. It is thus possible that the English does not exactly correspond to the German text; however, the 'spirit' of the text has been preserved. 
That being said, from a methodological standpoint, it indeed seems that the reflexive process which would enable the scholar to appreciate the acts which depend on this WE - which it is never excluded from - is not always considered essential in the processes we carry out to further knowledge. In fact, a methodology founded on the objectalization and decontextualization ${ }^{13}$ of the chosen object of study (an obviously necessary methodology for controlled, precise research configurations to circumscribe the phenomenon to be described and reduce its dependence on specific conditions) ${ }^{14}$ can have the effect of masking what should never be omitted: the constitutive relation to the "things" and "concepts" that researchers and/or communication actors develop dynamically through their comprehension. Thus there is rarely interest-in the field of study where we do what we do-in how we effectively do what we do, in the modalities and modalization of such doing, and subsequently, in the recognition if not in the description of this state of affairs. And yet this type of approach is highly informative both as knowledge per se and as a strategy for construing knowledge. ${ }^{15}$ So where do we stand? Where then is this WE? And, in the end, must it really be situated "somewhere"?

Let us take an image. As ordinary and academic communication actors, we are outside of WE given that we conceptualize it—and therefore reify it—and have the possibility of analyzing it within a descriptive process, but we are also inside WE because we continuously actualize it in our activity which it

13 At times this necessary methodology is ostentatiously displayed as proof (and guarantee) of the rigor of a scientist's approach. In some cases moreover it may drift from sound methods leading to conceptual receptiveness towards blind rigor inducing conceptual sclerosis.

14 It can naturally support the well advanced development of potentially formalizable linguistics which construes its objects and asymptotically elaborates its approaches in the perspective of "worthwhile" scientific reductionism in its framework; the validity of this approach is not being questioned, it has provided numerous useful results, within the boundaries it predefines. But only within these predefined boundaries!

15 Recall Maturana and Varela: "Knowing how we know does not consist of a linear explanation that begins with a solid starting point and develops to completion as everything become explained. Knowing how we know is rather like the boy in Escher's Picture Gallery. The picture he looks as is gradually and imperceptibly transformed into ... the city where the gallery and the boy are! We are unable to locate the starting point: Outside? Inside? The city? The boy's mind? Recognizing this cognitive circularity, however, does not constitute a problem for understanding the phenomenon of cognition. On the contrary, it constitutes the starting point the enables us to explain it scientifically ([1987] 1998: 244)". 
determines. One may then consider that WE functions on a single plane. With all the complexity of the dynamics which constitute it, this single plane is not that of languages, nor is it that of communication actors: it the plane which relates languages to their users and articulates them, the plane where communicational dynamics develop.

In consequence, independently of its constituent complexity, I will metaphorically interpret $\mathrm{WE}$ as manifesting the reciprocal and reflexive relations between languages and communication actors (us all) on this specific plane, construed as the paradoxical plane of a Möbius strip, constituting the dedicated space of our trajectory (Nicolaï, 2011:139, 2017c). A plane which we never leave, given that we are both the actors and the descriptors of communication and the languages we comprehend. I thus locate this WE in an enclosure wherein, on one hand, what is construed and/or grasped in communicational interactions and on the other hand, the actors who partake in these communicational interactions (ordinary speakers and descriptors) —all functioning as signsmanifest, articulate, mirror, determine and partake all together in construing and transforming forms and languages, all while developing meaning.

Actualizing within this single-surfaced loop, one can say that WE contributes to ascribing meaning and redefining what ensues, seamlessly linking and (re)contextualizing, continuously transforming the subjectivity of communication actors, the historicity of their usage and the materiality of the forms which they use through dynamics which punctuate the temporalization of our experienced continuity.

\subsection{The 'Münchhausen Trilemma'}

But what does all this allow us to postulate in terms of construing knowledge? Various issues can be introduced.

Is not this posited "reflexive and interactive loop" problematic for scholars from the perspective of explaining and clarifying what is happening? Is a position which is equivalent to considering that the "explainer" is an integral part — and on the same plane - as what is being explained "acceptable"? Does it hamper the "need for objectivity" of an undertaking labeled as "scientific"?

Should we not refuse this game of mirrors and the existence of the plane which actualizes it?

Would it not be better to set ourselves up as disembodied analysts projecting our thoughts onto this "strange place" whence we could imagine being in a better position to grasp these dynamics of the observed world, as if from Sirius?

Could this be "THE" solution? It can be doubted.

To argue these issues, I will once again "sidestep" them to examine general explanatory modalities, and will consider what is known as the Münchhausen 
trilemma ${ }^{16}$ which I will present here, summarized from the work of the sociologist R. Boudon in his illustration of what he calls the 'Simmel model':17

All scientific premises stem from a theory, and all theories are founded on principles. One of three things however, either one deduces these principles from other principles, in which case those also have to be demonstrated, and one ends up in an infinite regression; or one stops at principles which one considers intuitively and absolutely true; or one substantiates the principles in question in a circular fashion by taking into account their consequences. This is known as the "Münchhausen trilemma" inspired by the legendary baron who managed to extract himself from a pond in which he had accidentally fallen by pulling himself out by his own hair. ${ }^{18}$

\section{From the Möbius Strip to Circular Causality}

Let us now return to the topic of circularity. Given the particular structure of the Möbius strip, a little gnome could begin walking at a given point ' $\boldsymbol{a}$ ' on the strip, could explore everything there is to explore on the plane he is on, and will necessarily return to his starting point. The peculiarity of this structure

16 What this trilemma posits is not far removed from Popper's observation: "This is how we lift ourselves by our bootstraps out of the morass of our ignorance; how we throw a rope into the air and then swarm up it - if it gat any purchase, however precarious, or any little twig (1972: 148)". See also Nicolaï (2017b Chap. 5).

17 The best here would be to refer directly to Boudon (1990: 103 sq.), but I will very "aridly" attempt to specify the essentials. Given a theory containing the explicit premises 1) p ;2) $\mathrm{p} \rightarrow \mathrm{r}$; 3) $\mathrm{q} \rightarrow \mathrm{r}$; whence 4) $\mathrm{r}$. But what founds belief in $\mathrm{r}$ ? It can stem from an entire chain of apparently independent inferences and of implicit premises such as e.g.: 5) r ; 6) $r \rightarrow p$. Whence once concludes 7) p. Thus, in total, rather than a linear theory $\mathrm{T}$ composed of four propositions we have in fact a circular theory T', composed of seven propositions, of which three are implicit. In making the whole explicit, it becomes possible to understand the theory's circularity. A circularity which is masked in fact because of the implicit nature of the propositions which make it so.

18 [Toute proposition scientifique découle d'une théorie et toute théorie est fondée sur des principes. Or, de trois choses l'une, ou bien l'on déduit ces principes d'autres principes qu'il faut alors démontrer et l'on s'engage ainsi dans une régression à l'infini ; ou bien l'on s'arrête à des principes qu'on considère comme intuitivement et absolument vrais ; ou bien l'on étaie de façon circulaire les principes en question par leurs conséquences. C'est ce qu'on a appelé le « trilemme de Münchhausen », en souvenir de ce baron légendaire qui réussit à se sortir d'un étang dans lequel il était tombé par mégarde en se soulevant par sa propre chevelure (2000: 13)]. 
is that, without necessarily realizing it, he will have covered, with no break in continuity, both visible surfaces of the strip, because — counter intuitively—it only has one!

Moreover, let us consider Simmel's proposition which Boudon popularized; I will simply quote Simmel (1988: 80) after Boudon (1990:113), (italics are mine):

If one pursues the demonstration of a principle to its foundations, and then each of these to their foundations, etc., one often discovers, as is well known, that the demonstration is possible, i.e. can in turn be demonstrated, on condition that one considers as already demonstrated the first principle which it is supposed to demonstrate. If, applied to a given deduction, this renders it illusory like a vicious circle, it is by no means unthinkable that our knowledge, taken as a whole, is a captive of such a form. ${ }^{19}$

What we have here, as Boudon well showed, is a presentation of Simmel's epistemological reflection on the possible / potential circular nature of our epistemic construals. As Boudon says, considering the third figure in the trilemma:

One must freely admit that this trilemma has never prevented science from producing certainties. Why not? Because knowledge is circular, as Simmel well observed (1984). In the scientific domain, it is indeed the consequences which confirm or, on the contrary, infirm the principles, and the principles which enable the drawing of consequences. ${ }^{20}$

Thus the hypothesis that, generally speaking and without being aware of it, in the complex space within which we "function", we develop our epistemic construals in accordance with the third modality in the Münchhausen trilemma: that of the recursive causality which naturally offers us no logical truth, but nonetheless aids us in addressing the (ir)regularities of our world.

19 [Verfolgt man den Beweis eines Satzes in seine Begründungen und diese wieder in die ihrigen usw., so entdeckt man bekanntlich oft, dass der Beweis nur möglich, d. h. seinerseits beweisbar ist, wenn man jenen ersten, durch ihn zu beweisenden Satz, bereits als erwiesen voraussetzt. So sehr dies, für eine bestimmte Deduktion aufgezeigt, sie als einen fehlerhaften Zirkelschluss illusorisch macht, so wenig ist es doch undenkbar, dass unser Erkennen, al Ganzes betrachtet, in dieser Form befangen wäre (Simmel, 1907: 67)].

20 [Comme on l'admettra facilement, ce trilemme n'a jamais empêché la science de produire des certitudes. Pourquoi ? Parce que la connaissance est circulaire, ainsi que l'a bien vu Simmel (1984). Dans le domaine scientifique, ce sont effectivement les conséquences qui confirment ou au contraire fragilisent les principes et les principes qui permettent de fonder les conséquences $(2000: 13)]$. 


\subsection{Circularity as a de facto Horizon}

I don't know if this is always the case, but it seems to me that the choice of this third modality (circular reasoning), despite the stigmatization and methodological warning bells it sounds in logical minds, has at least the advantage of reducing the excesses of the two other types of reasoning which, not being singled out as being "alogical", are perhaps all the more aberrant. In effect, they are implicitly grounded in true ideological assumptions in presuming that to reach the Golden Age of knowledge-towards which we are supposed to be tending - we must, depending on which "ideological" option is chosen, either work our way infinitely back towards the proof that our premise is correctly founded on a rationally legitimate basis, but then of course it is necessary to seek the legitimate basis of that basis (i.e. infinite regression as far as the formalisms justifying the theorization are concerned); or swear allegiance to a "Master" (accepting without inspection the academic premise, axiom or expert opinion which ensures, ex cathedra, the validity of our world's forms). In both cases, the Eden of the sought after-and "stabilizing"-knowledge is located outside the enclosure within which we function. It would seem that Humans are always searching for transcendence.

That being said, it is important to remember that, from my perspective, these considerations on circular reasoning only apply to the work of epistemic development, which bears on a universe of which we are a constituent part and which, in fact, contains us! This is case of the social and conceptual empirical worlds in which we de facto function in our ordinary and scholarly social lives. And yet it remains possible to conceive of and construe "projected worlds", with more or less formal definitions of their nature and rules of procedure, and a greater or lesser degree of resemblance to the "real world", and to then establish their scope of relevance. In such "projected worlds" (whether formal or not, science or fiction) which we have the ability of construing, reasoning founded on the arguments of an authority or deducible from the theoretical framework explicitly predefined for a given conceptual universe can be legitimized to help us understand the dynamics and phenomena of our ordinary world; they are highly useful as "ad hoc models" - necessary intellectual props - or as "flights of fantasy" - useful mind refreshers. But it is difficult to forward this beyond work on (and grounded in) the image-model since we do not function as citizens of a Garden of Delights, nor as anonymous variables in a deductive theory.

\subsection{Back to the Land of Gnomes}

Let us now return to our gnome who has finished exploring the Möbius strip. We all know that gnomes have no desire for transcendence, they simply live 
their lives in the exploration of the world around them with unquenchable curiosity, they are always on the alert for a chance to better their understanding of what is going on around them. In short, they do not take into consideration nor refer to the "unknowable" outside of their enclosure to explain their (the) world. They simply develop life strategies in context and save up working recipes, the efficacy of which they continuously test to better profit from the world and make their way as best they can-which is not always easy! ${ }^{21}$ However they fully intend to explore all of the world's forms, all of its characteristics to establish, depending on the case, induced-and sometimes deducedthe rules behind its workings. Of course these rules are questioned anew each time they discover a new event which requires restructuring of the signifying whole which they had built up together, but that's how the game goes. In other words, our little gnome exploring the Möbius strip develops his comprehension of his world (which he never leaves and would not even consider abandoning) in accordance with the principle of circular causality. Jumping from cause to cause, he will eventually become familiar with all its details.

So what does this excursion in Gnome and Möbius strip land teach us? It highlights the enclosure within which we function and the fact that, since we are never outside ourselves, we construe knowledge, build our theories, and function in manifest circularity. In parallel, erasing and re-erasing an eternal palimpsest, we can refer once again (cf. note 9 supra) to Maturana and Varela who posit that it: "...will put us in a circular situation ([1987] 1998: 240)" and that, just like the chicken and the egg which function in the closed universe which they naturally actualize:

Nonetheless, we evidently cannot break away from this circle and step out of our cognitive domain ... The fact remains that we are continuously immersed in this network of interactions, the results of which depend on history. Effective action leads to effective action: it is the cognitive circle that characterizes our becoming, as an expression of our manner of being autonomous living systems ([1987] 1998: 241).

The lessons to be drawn from all of this appear opportune given that these epistemological and theoretical propositions, from Simmel to Boudon, Maturana and Varela (to limit myself to those I have cited), via the little gnomes we have crossed paths with... converge-grounded in other areas of knowledge

21 With Humans this would probably lead to the idea of Popperian falsifiability, but Gnomes are more modest! 
construal-with what the introduction of WE presupposes in my considerations derived from reflections on language contact and its dynamics.

\section{$9 \quad$ Back to the Initial Questions}

Following this stroll, I believe we are now slightly better armed, not to categorically answer the three questions raised at the beginning (which, at the least, would entail the - unacceptable-imposition of an authoritarian argument!), but to, considering them within the world we have construed, find pathways which would bring us closer to possible answers and establish methodological orientations useful for better exploring them.

- How does meaning emerge, both as a cognitive activity and as a socially significant activity?

It is certainly by examining this dynamic which, from constructs to givens, links the retention of historicity to the development of WE in a contextualized trajectory, that answers to the question can / will be found.

- What of our conception of what language contact is, in both its methodological and epistemological dimensions?

At empirical level, we know that language contact is an observable phenomenon; at theoretical level, it is an object which can be analyzed based on the principles of a selected theoretical framework. Moreover, we also know that it is a potentially functionalizable concept. In fact, it is a construed reality (triangulated by its phenomena, its representations and its validations). The methodologies which enable its comprehension are naturally correlated to the theoretical framework chosen for its understanding. A framework which may_or not-integrate elements of the approach which I have suggested here.

- What of the manner in which we build our corpora, given that they should illustrate the dynamism and heterogeneity of language practices?

More crucially than for the two preceding ones, this latter question depends on the theoretical framework, methodological propositions and epistemological positions which ground the attempt at comprehension. It would be presumptuous to answer it peremptorily. This is why, without avoiding the question, 
I will answer it by introducing two perspectives susceptible of providing more insight.

By way of a general summary, one may note that, although the starting point was not a philosophical approach but an elementary desire to understand the processes by which we ascribe meaning, the dynamics of our communicational practices (both ordinary and academic), and the way in which we elaborate signs and language, what I develop here also intersects with-without becoming one with-various hermeneutic reflections modulated for other purposes from Schleiermacher to Gadamer. It is true that these reflections remove us somewhat from the initial, practical question of the "narrow" comprehension of language contact considered as a topic in its own right. At the same time, this contributes to reconsidering this issue to put it in its place. In effect, exploring language contact should not necessarily be limited to circumscribing a field of research and creating an intellectual ghetto to enable its existence. Nor is it equivalent (without completely excluding it) to developing a specific disciplinary space following tested "political" practices, which would have for only horizon its imposition upon the academic and social landscape. Such dynamics have the perverse effect of eventually leading to the marginalization or even the obsolescence of the issue they are promoting because, seemingly protected by their boundaries and the (self-) affirmation of their existence, this approach does not have the means to perceive what holds it together and links it to the general issues which gave rise to its fore fronting, nor to conceive of what such fronting makes it possible to introduce.

That being settled, let us return to the premise of circular causality in our comprehension of phenomena and to consideration of our Möbius strip to inquire whether our affirmed presence on its singled planed surface and our more or less circular epistemic ascriptions of meaning are related to what we have long retained under the label hermeneutic circle, in one variant or another. Such an insertion into this framework is uncertain... and in any case, cannot happen within any old "circle" nor any old way! It therefore requires some thought.

It is certainly possible to find affinities between my approach-which, outside of any philosophical pretensions, arose out of the empirical study of languages: observation of contact between them, correlated thoughts on their dynamics, and the will to explore the processes by which these dynamics ascribe meaning - and Schleiermacher's view ([1829] 1835. French translation 1989, 173 et sq.) on commenting G.A. Friedrich Ast and reconsidering the 
hermeneutics of texts within an open space, beginning with languages and their words and ending with the comprehension of the world around us. ${ }^{22}$ The "spiral" hermeneutic modality which he thus appears to have posited to grasp the dynamics of our comprehension of what we choose to comprehendranging beyond texts of course-is naturally compatible with the implementation of circular causality ${ }^{23}$ and probably constitutes a holistic modality of it. It nonetheless does not enable comprehension of the continuous dynamics by which forms, languages and meanings change, which is the matter of my exploration and which I perceive empirically. That is to say the dynamics in which communication actors continuously partake, and through which they ascribe meaning to the/their world.

Let us now return to the communication actors, which we are, who "function" on the singled planed surface of a Möbius strip where they are situated-together and with their representations. There, it would appear that they undergo helical drift along the axis of a temporality, nourished and redefined at each instant by the flow of these representations and its relations to them; representations and relations which they actualize, construe and transform. There is thus actualization of the flow and the transformations generated on one hand by the historicity induced by their trajectories, the dynamics of which, as mentioned above, it preconstrains and predetermines; and on the other hand there is actualization of the practices of ascribing meaning (ordinary or academic) which they develop under the auspices of a potentially circular causality within the phenomenologies they partake in-which we partake in.

22 Ventilated at different levels of analysis: "just as the whole can only be understood from its parts, so the parts can only be understood from the whole (Schleiermacher [1829] 1835)" (Translated by M.D. from the French translation) [dass wie freilich das ganze aus dem einzelnen verstanden wird, so doch auch das einzelne nur aus dem ganzen verstanden werden könne], and also: "The progressive understanding of all details and parts of a whole begins organizing from the outset but is only ever temporary, a little more perfect the more parts we have a comprehensive view of, but always beginning with new uncertainty... (cf. the 1829 speeches ( $2^{\text {nd }}$ speech), Schleiermacher, 1989: 175)" (Translated by M.D. from the French translation) [[...] dass vom Anfang an fortschreitend das allmählige Verstehen alles einzelnen und der sich daraus organisierenden Theile des ganzen immer nur ein provisorisches ist etwas vollkommner, wen wir einen grösseren Theil übersehen können, aber auch wieder mit neuer Unsicherheit und wie in der Dämmerung beginnend,...].

23 This hermeneutic "spiral" has been amply highlighted in the literature on Schleiermacher. For example Fontaine-De Visscher: "is not... A flat circularity [...]. It is rather an infinite spiral of relations, deepening at each level of the analysis and of its interpretation" [... n'est pas ... une circularité plate [...]. Il s'agit plutôt d'une spirale infinie de relations, s'approfondissant à chaque niveau de l'analyse et de son interprétation (1991: 628)]. 
To be more precise. Is this really to be considered a "drift" generated by the dynamics of these processes? Undoubtedly. But why "helical"? Because to understand what is offering itself to us and to signify what we are attempting in context - independently of the consideration of any Schleiermacherian hermeneutic spirals, we de facto situate ourselves in the perspective of what I have called elsewhere semiotic dynamics (e.g. Nicolaï, 2011, 2016a, 2016b, 2017 b); which is to say a perspective within which, having integrated our subjectivity - our faithful sidekick - and our constant reanalyses of the preceding state, we begin (anew) each time in our present-with what we have at our disposal- "each another next first time" according to the phrase by and in the terms of Garfinkel (1967). We are thus eternal pilgrims who, having "digested" the historicity of our practices ... (re)construe once again significance and meaning. And this by transforming, in passing, language forms and structures. To be even more precise, by (re)constructing all accessible language data in the here and now, with or without "language contact" posited / identified as such (but generally... with!); or rather, by having integrated the issue of "language contact" as an ordinary dimension of normalcy in our ordinary communicational practices. Whence the helix which illustrates what I call the fallacy of an "eternal return" to our space which is each time transformed, each time reconstructed, but never identical because it is never through the same point that the "transformed persona" which we already are will cross... but only above!

Let us attempt an aphorism: the helical drift is our continuous, historicized dynamic; the hermeneutic spiral is the process which we activate, attempting to complete our space of reference by proceeding to its saturation.

\section{$11 \quad$ Methodological Grounding}

We can now return to the methodology to truly conclude with some perhaps more practical and useful considerations. It will be the epistemic position of the sociologist J.-CL. Passeron (1991) analyzing what he calls the assertoric space of a domain which I propose to retain here. It is as follows:

The assertoric space of a science presents [...] as a universe of meaning, organized by a language's concepts into a "discourse universe", containing all necessary signs - and only necessary signs - to provide a stable definition of meaning and its assertions on its world of construed facts. [...] The logical space of assertoric discourse is a universe of meaning where the operational inventory limits, semantically and syntactically, possible and 
acceptable formulations by making explicit the scope of its coherence. $[\ldots]$. This means that assertoric space is defined by the set of linguistic terms, operations and expressions linking, without any semantic breaks, all possible assertions on a world of "facts" to a conceptual system whether the facts are formal or empirical. ${ }^{24}$

Thus as a final answer to the questions which have been raised, one could say that it is important to have a dual approach: on one hand an approach which recognizes the perspectives and presuppositions inherent in our analyses, and, on the other hand, an approach which effectively consists of expanding and saturating (in the sense of bringing it to completion with regards to the questions raised) the epistemic space contextually opened to research and designed for that purpose (here the space predefined by the subdomain of language contact under exploration). This is enabled by the rational application and systematic exhaustion of the set of all possibilities which it authorizes based on explicitly recognized knowledge at instant $\mathrm{T}$ of its implementation. This brings together at once historicity, systematicity and transformation dynamics within an enclosure specifically given as predefined. An enclosure within which causality can only be circular. Whatever its momentary arbitrary value or its punctual adequacy to the realities under consideration.

I do not believe I have answered, either definitively or correctly, the questions which have been raised. However, these observations may perhaps serve as elements for deepening the domain of possible answers.

\section{Acknowledgments}

I am particularly thankful to Andrée Tabouret-Keller for reading this text so attentively. Her comments, as always, were highly relevant and allowed me to

24 [L'espace assertorique d'une science se présente [...] comme un univers de sens, organisé par les concepts d'un langage en un "univers du discours", contenant tous les signes qui lui sont nécessaires - et rien que les signes qui lui sont nécessaires - pour définir de manière stable le sens de ses assertions sur son monde de faits construits. [...] L'espace logique d'un discours assertorique est un univers de sens dont l'inventaire opératoire borne, sémantiquement et syntaxiquement, ses formulations possibles et acceptables en explicitant le champ de sa cohérence. [...]. C'est dire qu'un espace assertorique est défini par l'ensemble des termes, des opérations et des expressions linguistiques rattachant sans rupture sémantique à un système conceptuel, fût-il momentané, toute assertion possible sur un monde de "faits" - que ces faits soient formels ou empiriques]. 
improve upon the original. I am also grateful to Katja Ploog for her assistance and to Margaret Dunham for her translation of the original paper "Contact des langues, circularité et Nous" (https://www.academia.edu/31982359/). A version of this paper was presented at the Journées d'étude: Variedades de español en contacto con lenguas amerindias: sistemas en contacto o prácticas lingüísticas heterogéneas which were held in Paris (12-13 June, 2017).

\section{References}

Benveniste, Émile. 1966. Problèmes de linguistique générale. Paris: Gallimard.

Benveniste, Émile. 1974. Problèmes de linguistique générale II. Paris: Gallimard.

Boudon, Raymond. 1990. L'art de se persuader des idées douteuses, fragiles ou fausses. Paris: Fayard.

Boudon, Raymond. 200o. Pluralité culturelle et relativisme. Comprendre 1 (« Comprendre les Identités culturelles »): 311-339.

Fontaine-De Visscher, Luce. 1991. Le rôle du sujet dans l'interprétation. Une nouvelle lecture de Schleiermacher avec Manfred Frank. Revue Philosophique de Louvain 84: 6o6-634. Can be downloaded from the following site http://www.persee.fr/doc/ phlou_0035-3841_1991_num_89_84_6707.

Garfinkel, Harold. 1967. Studies in Ethnomethodology. Englewood Cliffs (NJ): Prentice Hall.

Maturana, Humberto R. and Varela Francisco J. [1987] 1998. The Tree of Knowledge. The Biological Roots of Human Understanding (translated by R. Paolucci). Boston: Shambale.

Nicolaï, Robert. 1986. Catégorisation pratique et dynamique linguistico-langagière (application à la morphosémantisation et aux constructions normatives). Langage et Société 35: 33-66.

Nicolaï, Robert. 2001. Exploration dans l'hétérogène: miroirs croisés. Cahiers d'études africaines 163-164: 399-421.

Nicolaï, Robert. 2011. La construction du sémiotique. Réflexion sur les dynamiques langagières et l'activisme des acteurs. Paris: L'Harmattan.

Nicolaï, Robert. 2012. Phénomènes et mise en signification: remarques adventices. Langage et Société 142: 59-72.

Nicolaï, Robert. 2013. (with K. Ploog): Frontières. In Jacky Simonin and Sylvie Wharton (eds.). Sociolinguistique du contact. Dictionnaire des termes et concepts. Lyon: ENS Éditions.

Nicolaï, Robert. 2016a. Langues, dynamique sémiotique, pertinences: des devanciers et des contemporains. Langage et Société 158: 109-127. 
Nicolaï, Robert. 2016b. Fonctionnalisme et création de sens. La perspective de la dynamique sémiotique. International conference on the occasion of the $90^{\text {th }}$ anniversary of the Prague Linguistic Circle. Prague, 24-26 October, 2016. Can be downloaded from the following site https://www.academia.edu/25671945.

Nicolaï, Robert. 2017a. Meanderings around the notion of 'contact' in reference to languages, their dynamics, and to 'WE'. Journal of Language Contact 10(3).

Nicolaï, Robert. 2017b. Signifier. Essai sur la mise en signification dans l'espace épistémique et dans l'espace communicationnel ordinaire, Lyon: ENs Éditions.

Nicolaï, Robert. 2017c. Danse des interprétants, rémanence de l'historicité... et nous, (ouverture vers quelques questionnements "hors champ"). Colloquium: Le Cours de Linguistique Générale. 1916-2016 (Open workshop “Linguistics and semiotics” Geneva, 12-13 January, 2017). Can be downloaded from the following site https://www.aca demia.edu/30499468.

Nicolaï, Robert. (in press a). Comparer pour (trouver) quoi? Ce qu'on cherche et ce qu'on trouve en linguistique, et en général.

Nicolaï, Robert. (in press b). From geographical and social boundaries to epistemic breaks. In Jeroen Darquennes, Joe Salmons and Wim Vandenbussche (eds.) Language Contact, Handbücher zur Sprach-und Kommunikationswissenschaft. Berlin: de Gruyter.

Nicolaï, Robert. (in press c). Sous le dessin et le dessein, ou les conditions de la frontière et de l'émergence du sens. In Michelle Auzanneau and Luca Greco (eds.) Dessiner les frontières. Lyon: ENs Éditions.

Passeron, Jean-Claude. 1991. Le raisonnement sociologique. L'espace non-poppérien du raisonnement naturel. Paris: Nathan.

Popper Karl, R. 1972. Objective Knowledge. An Evolutionary Approach. Oxford: Oxford University Press.

Schleiermacher, Friedrich D.E. 1835. Reden und Abhandlungen der König. Akademie der Wissenschaft. Berlin. Can be downloaded from the following site https://www .digitale-sammlungen.de. (French translation by Chr. Berner: 1989. Herméneutique: Pour une logique du discours individuel. Discours de 1829. Paris: Éditions du Cerf).

Simmel, Georg. 1988. Philosophie de l'argent. Paris: Presses Universitaires de France. (French translation of Philosophie des Geldes $\left(1900,2^{\text {nd }}\right.$ ed. 1907) by S. Cornille and Ph. Ivernel).

Simmel, Georg. 1984. Les problèmes de la philosophie de l'histoire. Une étude d'épistémologie. Paris: Presses Universitaires de France. (French translation by R. Boudon of the $5^{\text {th }}$ edition (1923) of: Die Probleme der Geschichtsphilosophie. Eine erkenntnistheoretische Studie. Munich and Leipzig: Von Duncker and Humblot). 